\title{
Mobile Signal Path Losses in Microcells behind Buildings
}

\author{
Saulius JAPERTAS, Vitas GRIMAILA \\ Dept. of Telecommunications, Kaunas University of Technology, K. Donelaičio str. 73, 44249 Kaunas, Lithuania \\ saulius.japertas@ktu.lt, vitas.grimaila@ktu.lt \\ Submitted June 29, 2016 / Accepted December 12, 2016
}

\begin{abstract}
The paper presents measurement results of the GSM (900 MHz band), UMTS (2100 MHz band), and LTE (1800 MHz band) propagation path loss (PL) in the urban area behind the buildings of ten different heights. The results were compared with the 7 most popular models. It was found that the existing models approximate the experimental results with relatively large errors. The new model, which evaluates the path loss variation nature behind the buildings, is proposed. This new model shows good agreement with measurements for all three mobile technologies. The average relative error is less than $6.5 \%$.
\end{abstract}

\section{Keywords}

Cellular networks, radio wave propagation, mobile communications

\section{Introduction}

The number of mobile phone users is growing at high speed. This is related more to data services demand growth than to the needs of a voice service. Some of mobile phone manufacturers predict that the number of smart phone users will be more than 9.1 billion by 2020 [1]. The data transfer rate, compared with 2015, will increase 8 times and monthly global mobile data traffic will exceed 24.3 exabytes by 2019 [2]. Therefore, it will be necessary for such technologies, which can provide the high data transmission speed and quality. It will be done in the development of new technologies (5G and other) as well as improving the existing ones.

Most countries plan that $5 \mathrm{G}$ technology will be realized at frequencies exceeding $10 \mathrm{GHz}$ [3]. However, as it is well known, the increase in frequency causes the decrease of the distance between the base station (hereinafter BS) and User Equipment (hereinafter UE). Therefore, it can be assumed that high speed data will be ensured at the relatively short distances: less than $500 \mathrm{~m}$ between the BS and the UE. The mobile coverage planning becomes very important in this case. The accuracy of this planning will be determined by the propagation model accuracy. In this way, the models assessing different effects in the microcells will require the $5 \mathrm{G}$ networks planning. Those effects are: reflection, diffraction, refraction, scattering, shadowing, and penetration. However, in order to investigate the
$5 \mathrm{G}$ it is necessary to have deeper knowledge of the mobile signal propagation characteristics in the microcells for already existing technologies.

The main objectives of this work is to experimentally investigate the path losses in microcells for GSM, UMTS, LTE technologies, to compare these experimental data with the existing propagation prediction models and, if necessary, to propose a new path loss model. This work is continuation of [4] where the $2 \mathrm{G}$ technology signal propagation behind the buildings is analyzed.

\section{Related Works}

Currently, there are quite a lot of models (it is possible to charge more than 60), which allow to assess the propagation losses both in macrocells and microcells. All these models have certain limitations: according to frequency, to the distances between base station BS and user equipment UE, to BS and UE antenna heights, etc. Okumura-Hata and COST 231 Hata are the most popular propagation loss prediction models in macrocells. The path losses in the microcells are usually predictable using Walfish-Ikegami, LEE, ECC 33, Two slope, SUI, and other models. All these models are the functions of the distance between the BS and UE $d_{\mathrm{BS}}$, frequency $f$, BS and UE antenna highs $h_{\mathrm{BS}}$, and $h_{\mathrm{UE}}$ respectively, certain correction coefficients groups $C_{\mathrm{n}}$ :

$$
P L=\phi\left(d_{\mathrm{BS}}, h_{\mathrm{BS}}, h_{\mathrm{UE}}, f, C_{\mathrm{n}}\right) .
$$

Some microcells models try to assess the diffraction and reflection effects using additional parameters, such as: the certain angles $\alpha$, building heights $h_{\mathrm{b}}$, certain spaces (street width) dimensions $d_{\mathrm{r}}$ (e.g., Walfish-Ikegami model) or terrain roughness $h_{\mathrm{t}}$ (Lee models). The path losses are described as the function in (2):

$$
P L=\phi\left(d_{\mathrm{BS}}, h_{\mathrm{BS}}, h_{\mathrm{UE}}, f, C_{n},\left\{\begin{array}{l}
\alpha, h_{\mathrm{b}}, d_{\mathrm{r}} \\
h_{\mathrm{t}}
\end{array}\right) .\right.
$$

Some of the works in order to approximate the path losses data in the microcells use models that formally have to be applied only in the macrocells (Okumura-Hata, COST 231 Hata, etc.) [4-9]. However, these macrocell models results do not differ from microcells models (WalfishIkegami, ECC 33, Two slope, etc.) results according to the 
accuracy. The above-mentioned works very clearly show this. The works' analysis shows that only certain models at the certain distance from the BS areas may coincide with the experimental results. But at the other distances, the same model results differ from experimental results rather significantly. In particular, the experimental and theoretical results show the clear mismatches in short distances from BS. The experimental results in [7] are well approximated using the SUI model but only over the distances of $300 \mathrm{~m}$. The error between the experimental and model results can reach up to $30 \%$ when the distances are shorter. The experimental results in [8] are compared with the WalfishIkegami model results; it is seen that at the distances from the BS shorter than $500 \mathrm{~m}$ the results mismatch is significantly higher than $10 \%$. In addition, these experimental results show the clear results scattering similar to the slow fading influence. And it does not depend on the frequency and area (urban or suburban) where measurements are carried out [10]. However, none of models does not evaluate such results scattering. Sometimes there is an attempt to modify the known model using the obtained experimental results. But often such modified models provide not sufficiently good approximations even for the experimental results which were received at the same work. For example, in [11] the optimized Hata model is proposed, it gives good result coincidences in BS1 and BS3 stations. Meanwhile the error can reach about $10 \%$ for the BS4 case in the distances between $500 \mathrm{~m}$ and $1000 \mathrm{~m}$. Furthermore, there is clearly seen that the errors between the experiment and modeling results are significant at less than $200 \mathrm{~m}$ distances.

The received results are spread out in the wide range of path losses values and seem as the certain „Swarm“ when the sufficient number of experimental measurements are carried out in the microcells [12-15]. Such "swarm" is also observed at short distances between BS and UE (less than $200 \mathrm{~m}$ ) when the frequency is high enough (>20 GHz) [16-18].

Thus, the works' analysis shows that there is still important to investigate the path loss changes in the microcells, especially for short distances between BS and UE.

\section{Experimental Setup}

The two base stations (hereinafter BS1 and BS2) near Kaunas University of Technology have been chosen for the experiments. The areas around BS1 and BS2 are densely populated. These base stations support GSM (EDGE), UMTS and LTE mobile technologies. Buildings of different heights, at the distances less than $50 \mathrm{~m}$ from each other, are in BS1 and BS2 coverage areas. The path losses variation of GSM, UMTS and LTE in BS1 coverage area and only GSM path losses variation in the BS2 coverage area were researched. BS1 frequency for the GSM is $956 \mathrm{MHz}$, for the UMTS is $2127 \mathrm{MHz}$, for the LTE is $1819 \mathrm{MHz}$. $\mathrm{BS} 1$ antennas height $h_{\mathrm{BS} 1}$ is $43 \mathrm{~m}$, ERP (equivalent radiated power) is $62.82 \mathrm{dBm}$ for UMTS, and LTE for GSM ERP is $38.81 \mathrm{dBm}$. BS2 frequency (GSM) is $945 \mathrm{MHz}$, antennas height $h_{\mathrm{BS} 2}$ is $32 \mathrm{~m}$ and ERP is $40.01 \mathrm{dBm}$. Receiver (UE) antennas height $h_{\mathrm{UE}}$ was constant at $1.3 \mathrm{~m}$.

Table 1 summarizes the main experimental parameters. $h_{\mathrm{b}}$ means the height of the building, $d_{\mathrm{BS}}$ means the distance between the base station and the measurement point.

The signal strength measurements were carried out with a spectrum analyzer Anritsu Cell Master MT8212A; its frequency measurement range is from $10 \mathrm{MHz}$ to 3.0 GHz. The results were processed using specialized software Handheld Software Tools (HHST 6.61). The measurements were carried out up to $500 \mathrm{~m}$ distance from the base station. UMTS and LTE signals were simultaneously measured and recorded in the spectrum analyzer's memory. GSM signal strength measurements were carried out at other times in similar weather conditions. The signal strength characteristics of behind the 17 buildings whose height varied from 6 to $41 \mathrm{~m}$ were measured. In some cases, buildings of the same height are at different distances from the BS. The measurements were carried out behind the building. The first measurement point was chosen at the distance of $1 \mathrm{~m}$ from the rear (with respect to the BS) wall of the building. The signal strength was measured every $5 \mathrm{~m}$ (UMTS and LTE) and $2 \mathrm{~m}$ (GSM), gradually moving away from the house. Ten measurements

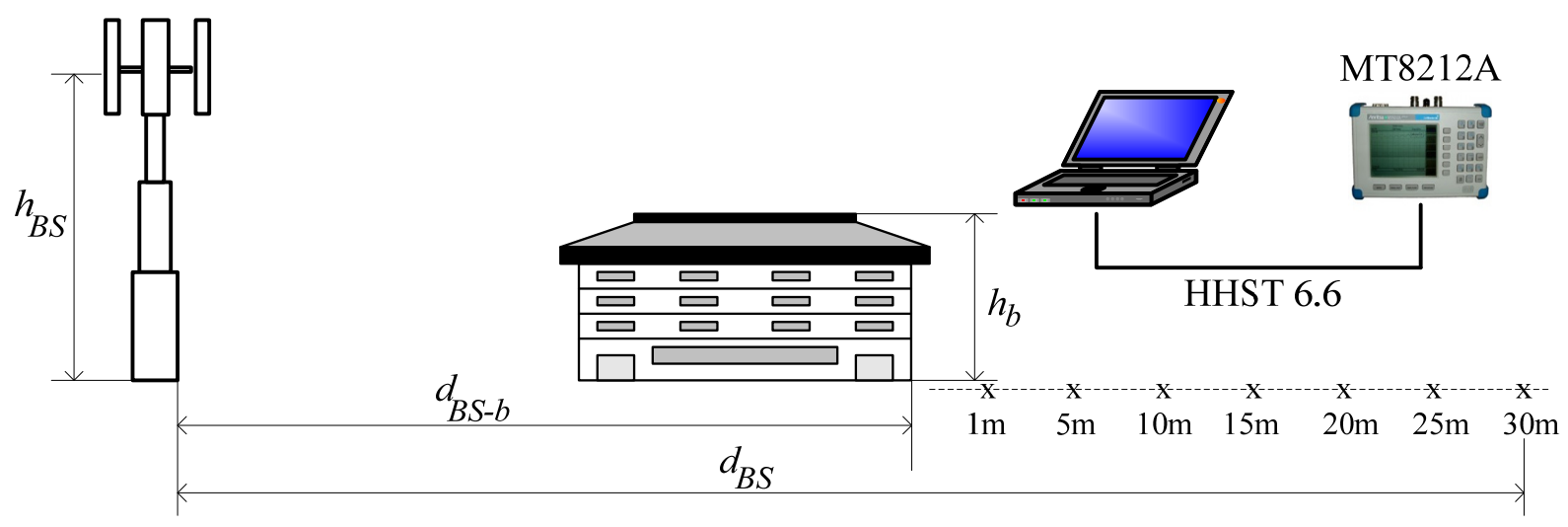

Fig. 1. Experiment scheme (sign $x$ means the measuring point). 


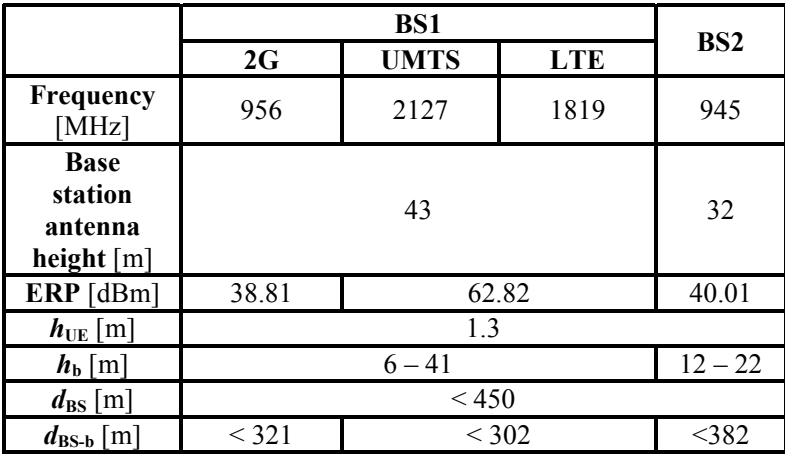

Tab. 1. Experimental parameters.

were carried out in each point and the results were averaged. The experiment scheme is shown in Fig. 1 . The $h_{\mathrm{BS}-\mathrm{b}}$ means the distance from the BS to the building far edge.

The various errors were calculated in order to evaluate the results accuracy according to (3): the relative error $\delta$, the root-mean-square of the measurement result, the rootmean-square of the measurements' mathematical expectation, dispersion $\sigma$ and skewness $\gamma$ :

$$
\left\{\begin{array}{l}
\delta=\frac{\frac{1}{n}\left|R S L_{i}-\langle R S L\rangle\right|}{\langle R S L\rangle} \cdot 100 \%, \\
\sigma=\frac{1}{n} \sum_{i=1}^{n}\left(R S L_{i}-\langle R S L\rangle\right)^{2}, \\
S_{\mathrm{RSL}}=\sqrt{\frac{\sum_{i=1}^{n}(R S L-\langle R S L\rangle)^{2}}{n-1}} \\
S_{\langle\mathrm{RSL}\rangle}=\frac{S_{\mathrm{RSL}}}{n}, \\
\gamma=\frac{\frac{1}{n} \sum_{i=1}^{n}\left(R S L_{i}-\langle R S L\rangle\right)^{3}}{\left(S_{\mathrm{RSL}}\right)^{3}} .
\end{array}\right.
$$

where $R S L_{i}$ is the signal strength of the separate measuring, $\mathrm{dBm} ;\langle R S L\rangle$ is the mathematical expectation, $\mathrm{dBm} ; n$ is the number of measurements.

By summarizing all received errors it was found that the average relative error $\delta$ is about $4 \%$ for all measurements, the root-mean-square $S_{\mathrm{RSL}}$ is about $1.63 \mathrm{dBm}$, the root-mean-square of the measurement mathematical expectation is $S_{\langle\mathrm{RSL}\rangle}$ is about $0.47 \mathrm{dBm}$, the dispersion $\sigma$ is about 9.55 .

\section{Results}

The path loss dependence on technology and the distance $d_{\mathrm{BS}}$ is shown in Fig. 2. Very clear dependence on technology can be seen there. The biggest path loss is observed on LTE technology and the lowest to GSM (EDGE). It is seen that the path losses react stronger to the increase of $d_{\mathrm{BS}}$ for GSM technology than for UMTS or LTE.

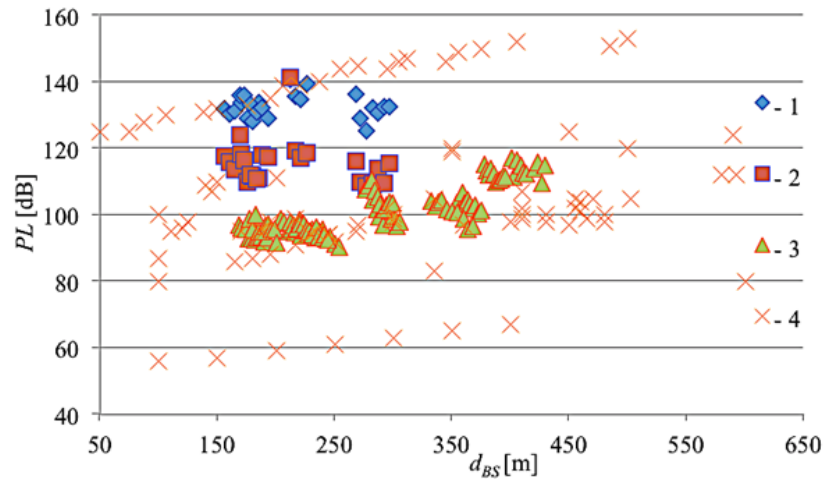

Fig. 2. Comparison of experimental results with the results of [5-7, 19-21]: LTE path loss - 1; UMTS path loss - 2; GSM path loss -3 ; results of $[5-7,19-21]-4$.

It can be seen that the results in Fig. 2 are similar to "swarm", as in the results of the other authors. Such "swarm" of the results is due to the fact that results are shown without taking into account the measurement environment of a particular case: the influence of buildings, the measuring point location behind the buildings, the building height, whether the measured path loss is on the line of sight or non-line of sight with the base station, influence of trees, etc. All these environmental factors influence the path losses and, in order to make very accurate assessment of path losses, it is necessary to take into account these factors.

The cumulative distribution function CDF dependence on the path losses for different mobile technologies is shown in Fig. 3; it shows that using more sophisticated signal-forming technology shifts curve to the right. This fact statistically demonstrates that the higher-generation mobile technologies lead to higher path loss. The slope of the curves shows that the smallest errors are received for LTE technology, when the largest errors are for GSM technology. It seems that the highest technology gives the better accuracy.

The experimental path losses results are compared with the most popular 7 models results (Fig. 4); these models approximated the experimental results with relatively high errors. Table 2 summarizes the main propagation model expressions.

However, there is at least one model for the different technologies that allows to evaluate the experimental re-

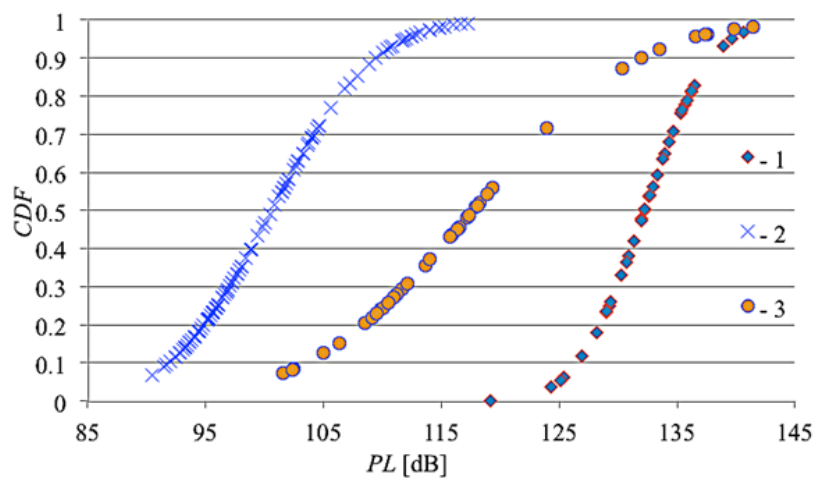

Fig. 3. Experimental path loss CDF for different mobile technologies: LTE - 1, UMTS - 2, GSM - 3 . 


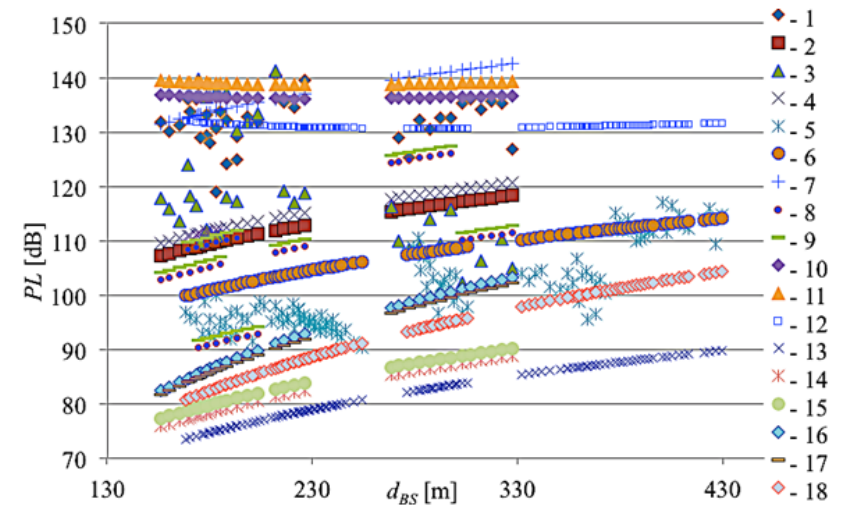

Fig. 4. Comparison of experimental results with some models prediction results: LTE experiment -1 , COST231Hata (LTE) - 2, UMTS experiment - 3, COST231Hata (UMTS) - 4, GSM experiment - 5, Okumura Hata (GSM) - 6, Multislope (LTE) - 7, WalfishIkegami (LTE) - 8, Walfish-Ikegami (UMTS) - 9, ECC 33 (LTE) - 10, ECC 33 (UMTS) - 11, ECC 33 (GSM) - 12, Clutter Factor (GSM) - 13, Clutter Factor (LTE) - 14, Clutter Factor (UMTS) - 15, Two slope (UMTS) - 16, Two slope (LTE) - 17, Two slope $(\mathrm{GSM})-18$.

sults with reasonable errors. For the GSM, the best results ( $\delta$ is about $18 \%$ ) are achieved with the SUI and OkumuraHata models; Hata model gives the best results $(\delta$ is about $30 \%)$ for UMTS; and Multi-slope model gives the best results ( $\delta$ more than $10 \%)$ for LTE.

The other fact is also seen in Fig. 4. Although in general, the path losses increase with the $d_{\mathrm{BS}}$ increasing. The path losses behind the buildings relatively decrease with the distance from BS.

A few things can be seen after analyzing the path losses variation for the different building height and for the different mobile technologies. In particular, this path loss variation can be approximated by linear equation $P L=a \cdot d_{\mathrm{BS}}+b$. In addition, when the height of the buildings $h_{\mathrm{b}}$ is the same, but $d_{\mathrm{BS}}$ is different, the $P L$ variation can be approximated with the parallel straight lines i.e., the slope of the straight line which is defined by coefficient $a$ does not depend on $d_{\mathrm{BS}}$, but it depends on $h_{\mathrm{b}}$. Moreover, this coefficient does not strongly depend on mobile technology. The typical examples of these experiments are shown in Fig. 5.

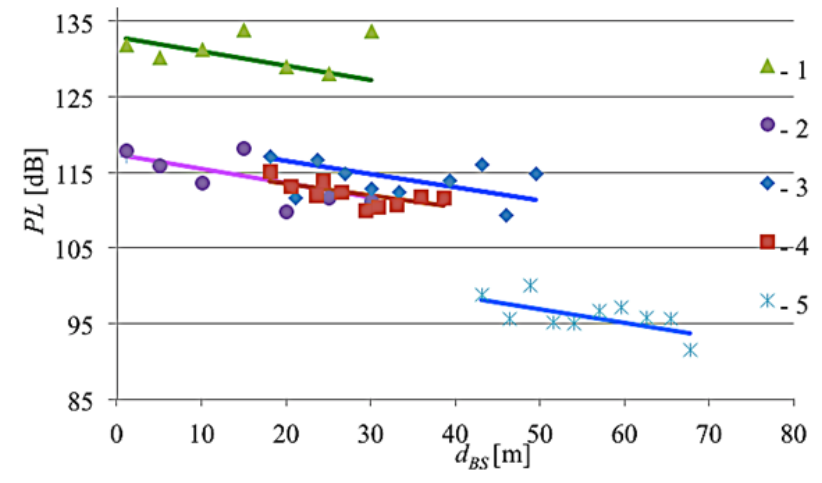

Fig. 5. Path losses variation vs distance behind the building for $18 \mathrm{~m}$ high buildings: LTE - 1, UMTS - 2, GSM $3-5$, approximation of results - solid lines.

\begin{tabular}{|c|c|}
\hline Model & Description \\
\hline $\begin{array}{l}\text { Okumura } \\
\text { Hata }\end{array}$ & $\begin{array}{c}P L=69.55+26.16 \cdot \lg (f)-13.82 \cdot \lg \left(h_{\mathrm{b}}\right)- \\
a\left(h_{\mathrm{m}}\right)+\left[44.9-6.55 \cdot \lg \left(h_{\mathrm{b}}\right)\right] \cdot \lg (d)^{b}, \\
\left.a\left(h_{\mathrm{m}}\right)=3.2 \cdot\left[\lg \left(11.75 \cdot h_{\mathrm{m}}\right)\right]^{2}-4.97\right), \\
b=1, d \leq 20 \mathrm{~km}\end{array}$ \\
\hline $\begin{array}{c}\text { COST231- } \\
\text { Hata }\end{array}$ & $\begin{array}{l}P L=46.3+33.9 \cdot \lg (f)-13.82 \cdot \lg \left(h_{\mathrm{b}}\right)- \\
\quad a\left(h_{\mathrm{m}}\right)+\left[44.9-6.55 \cdot \lg \left(h_{\mathrm{b}}\right)\right] \cdot \lg (d)+C_{\mathrm{m}} ; \\
\left.a\left(h_{\mathrm{m}}\right)=3.2 \cdot\left[\lg \left(11.75 \cdot h_{\mathrm{m}}\right)\right]^{2}-4.97\right) .\end{array}$ \\
\hline Two slope & $\begin{array}{l}L_{\mathrm{NEAR}}=L_{\mathrm{OH}}\left(d_{\mathrm{BP}}\right)+\text { slope }_{\mathrm{L}}\left[\lg (d)-\lg \left(d_{\mathrm{BP}}\right)\right], \\
\text { slope }_{\mathrm{L}}=\frac{L_{\mathrm{BP}}\left(d_{\mathrm{BP}}\right) \cdot \lg \left(d_{\mathrm{BP}}\right)-L_{\mathrm{FS}}\left(d_{20}\right) \cdot \lg \left(d_{20}\right)}{\lg \left(d_{\mathrm{BP}}\right)-\lg \left(d_{20}\right)}\end{array}$ \\
\hline $\begin{array}{l}\text { Multi- } \\
\text { slope }\end{array}$ & $\begin{array}{l}L_{3 \mathrm{~S}}= \\
32.44+20 \cdot \lg (f)+10 \cdot \lg \left[\frac{d^{2}+\left(h_{\mathrm{b}}-h_{\mathrm{m}}\right)^{2}}{10^{6}}\right], \\
d<0.04 \mathrm{~km} ; \\
L_{3 \mathrm{~S}}= \\
L\left(d_{40}\right)+\frac{\lg (d)-\lg \left(d_{40}\right)}{\lg \left(d_{100}\right)-\lg \left(d_{40}\right)} \cdot\left[L\left(d_{100}\right)-L\left(d_{40}\right)\right], \\
0.04 \mathrm{~km}<d<0.1 \mathrm{~km}\end{array}$ \\
\hline ECC 33 & $\begin{aligned} P L= & A_{\mathrm{fs}}+A_{\mathrm{bm}}-G_{\mathrm{t}}-G_{\mathrm{r}} ; \\
A_{\mathrm{fs}}= & 92.4+\lg (d)+\lg (f) ; \\
A_{\mathrm{bm}}= & 20.41+9.83 \cdot \lg (d)+7.89 \cdot \lg (f)+ \\
& 9.56 \cdot[\lg (f)]^{2} ; \\
G_{\mathrm{t}}= & \lg \left(\frac{h_{\mathrm{b}}}{200}\right) \cdot\left[13.958+5.8 \cdot(\lg (d))^{2}\right] ; \\
G_{\mathrm{r}}= & {[42.5742+13.7 \cdot \lg (f)] \cdot\left[\lg \left(h_{\mathrm{m}}\right)-0.585\right] . }\end{aligned}$ \\
\hline $\begin{array}{l}\text { Walfish- } \\
\text { Ikegami }\end{array}$ & $L_{\mathrm{b}}= \begin{cases}L_{\mathrm{o}}+L_{\mathrm{rts}}+L_{\mathrm{msd}}, & L_{\mathrm{rts}}+L_{\mathrm{msd}}>0 ; \\
L_{\mathrm{o}}, & L_{\mathrm{rts}}+L_{\mathrm{msd}} \leq 0 .\end{cases}$ \\
\hline $\begin{array}{l}\text { Clutter } \\
\text { Factor }\end{array}$ & $\begin{array}{l}L=40 \cdot \lg (d)+20 \cdot \lg \left(f_{\mathrm{c}}\right)-20 \cdot \lg \left(h_{\mathrm{b}}\right)+L_{\mathrm{m}} \\
h_{\mathrm{b}}, h_{\mathrm{m}}<<d, L_{\mathrm{m}}=76.3-10 \cdot \lg \left(h_{\mathrm{m}}\right)\end{array}$ \\
\hline
\end{tabular}

Tab. 2. Propagation model expressions.

The path losses variation for $18 \mathrm{~m}$ high buildings at different distances from the behind the buildings $d_{\mathrm{BS}}$ are shown there. Qualitatively similar results are observed in all other experiments.

The coefficient $b$ determines the initial path loss level at the first measurement point behind the building and it should depend on the distance from the building and frequency. The variation of the straight coefficients $a$ and $b$, depending on height of building and distance from the building, respectively is shown in Fig. 6 and Fig. 7 .

Figure 6 shows that the coefficient $a$ decreases with the increasing of the building height and the decrease is approximated according to line equation (4) with the mean relative error $\delta$ of about $7.96 \%$.

$$
a=-\left(0.0037 \cdot h_{\mathrm{b}}+0.1249\right) \text {. }
$$




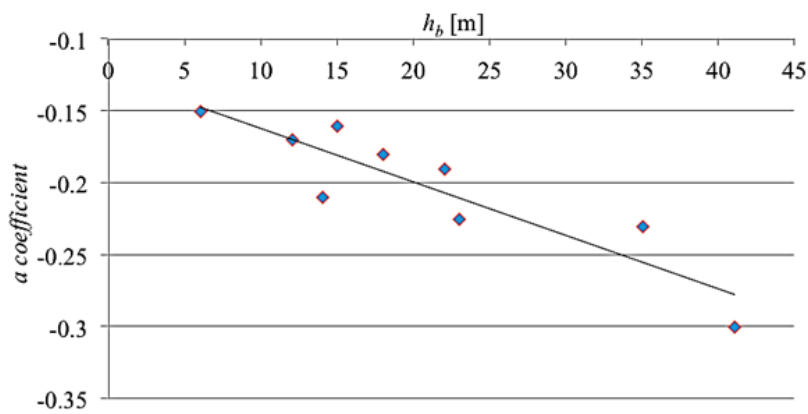

Fig. 6. $a$ coefficient variation vs the building high $h_{\mathrm{b}}$ : experimental data -1 , approximation of results - solid line.

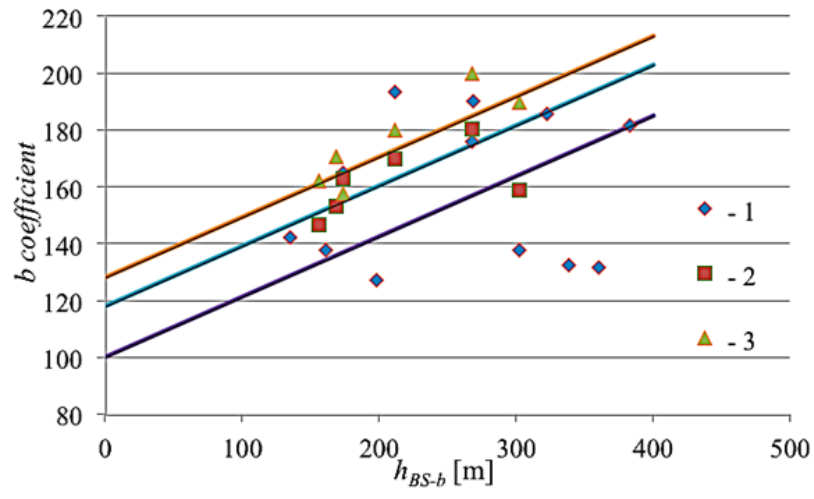

Fig. 7. $b$ coefficient variation vs distance from $\mathrm{BS} d_{\mathrm{BS}-\mathrm{b}}$ : GSM - 1, UMTS - 2, LTE - 3, approximation of results - solid lines.

The variation of the coefficient $b$, as can be seen from Fig. 7, depends on the distance from the BS to the building $d_{\text {BS-b }}$, mobile technology and frequency $f$. The variation of the coefficient $b$ could be approximated with the parallel line equations (5) for all experimental cases independently from the mobile technology:

$b=\left(0.2125 \cdot d_{\mathrm{BS}-\mathrm{b}}+20 \lg f_{[\mathrm{MHz}]}+\left\{\begin{array}{l}40.4 \ldots \text { for GSM } \\ 51.5 \ldots \text { for UMTS } \\ 62.8 \ldots \text { for LTE }\end{array}\right)\right.$.

Comparing the results of the model with the experimental results it was noticed that in some cases the error exceeds $10 \%$. It was observed that when $\operatorname{tg} \alpha$ (Fig. 8) is less than 0.05 , then there is the need to add the correction factor $C F$. In this case equation (5) is:

$b=\left(0.2125 \cdot d_{\mathrm{BS}-\mathrm{b}}+20 \lg f_{[\mathrm{MHz}]}+\left\{\begin{array}{l}40.4 \ldots \text { for GSM } \\ 51.5 \ldots \text { for UMTS } \\ 62.8 \ldots \text { for LTE }\end{array}\right)\right.$.

$(-8.98 \cdot \operatorname{tg} \alpha+1.436)$.

Equation (5) and (6) approximate experimentally determined values of coefficient $b$ with the following mean relative error: for GSM $\delta$ is about $6.47 \%$, for UMTS $\delta$ is about $4.75 \%$ and for LTE $\delta$ is about $3.85 \%$. Thus, by evaluating (4), (5) and (6), the path losses behind the buildings in microcells can be approximated by the equation:

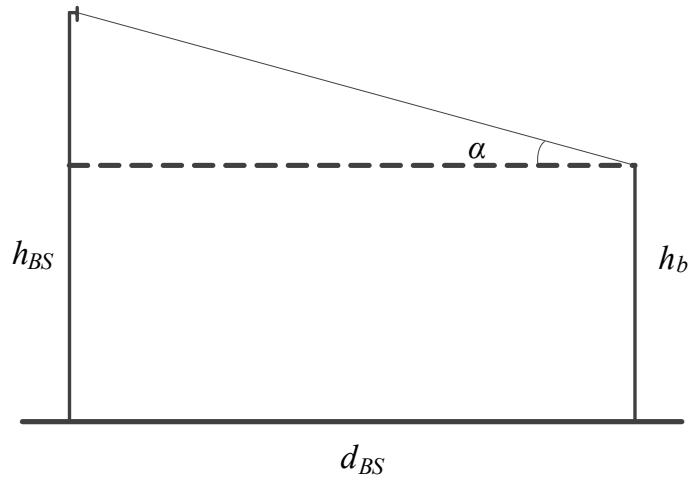

Fig. 8. Diagram explaining the angle $\alpha$.

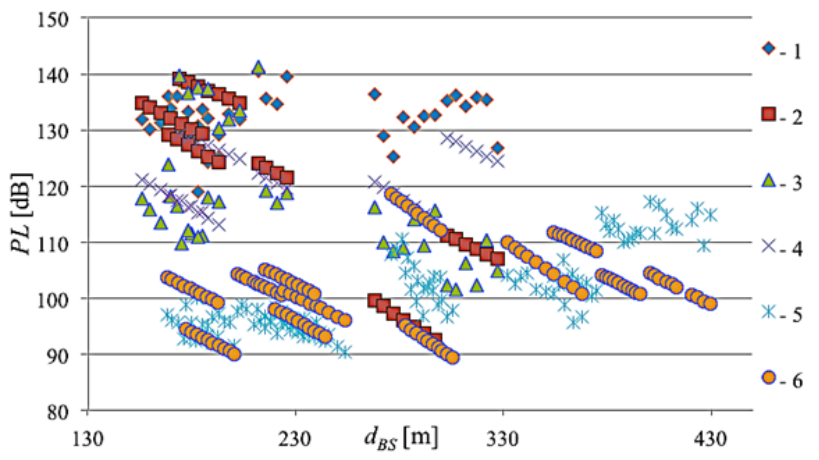

Fig. 9. Comparison of experimental results with the proposed model (7) results: LTE experimental results -1 , LTE model - 2, UMTS experimental - 3, UMTS model - 4, GSM experimental -5 , GSM model -6 .

$$
\begin{aligned}
P L & =-\left(0.0037 \cdot h_{\mathrm{b}}+0.1249\right) \cdot d_{\mathrm{BS}}+ \\
& \left(0.2125 \cdot d_{\mathrm{BS}-\mathrm{b}}+20 \lg f_{[\mathrm{MHz}]}+\left\{\begin{array}{l}
40.4 \ldots \text { for GSM } \\
51.5 \ldots \text { for UMTS } \\
62.8 \ldots \text { for LTE }
\end{array}\right) \cdot C F\right.
\end{aligned}
$$

where $C F$ is 1 if $\operatorname{tg} \alpha>0.05$ and $C F$ is $(-8.98 \cdot \operatorname{tg} \alpha+1.436)$ if $\operatorname{tg} \alpha \leq 0.05$.

The comparisons of the experimental results with the proposed model results are shown in Fig. 9.

The results coincide well enough and the average relative error does not exceed $6.5 \%$. The calculated skewness $\gamma$ shows that the deviation of the experimental results from the mean (mathematical expectation) is low, because $\gamma_{\text {LTE }}<3.2 \times 10^{-7} ; \quad \gamma_{\text {UMTS }}<7.2 \times 10^{-7} ; \quad \gamma_{\mathrm{GSM}}<1.1 \times 10^{-5}$, i.e. in all cases $\gamma \rightarrow 0$.

\section{Conclusions}

Path losses variation with the distance from BS behind the building with different heights for GSM, UMTS and LTE mobile technologies were compared with the results of seven models. It was found that no one of the models describes the experimental results with acceptable accuracy. In addition, these models do not explain certain experimental results scattering, which has the pattern character. 
It was found that the path losses decrease behind the building, when the distance from base station increases. This decreasing may be affected of such electromagnetic wave propagation mechanisms as shadowing and diffraction. Such decreasing, in our view, would take place up to position behind the house, where the line-of-sight conditions would start.

It was found that in addition to the generally accepted parameters, such as: $E R P, f, d_{\mathrm{BS}}, h_{\mathrm{BS}}, h_{\mathrm{UE}}, h_{\mathrm{b}}$, path losses are affected by the mobile technology.

The new path losses evaluation model in microcells behind the buildings is proposed. The comparison of the experimental and modeling results gives the error of approximately $6 \%$. This model describes the path losses for GSM, UMTS and LTE mobile technologies. The limits of the results validity are: $h_{\mathrm{BS}}>h_{\mathrm{b}}$, frequency range is $900 \mathrm{MHz}<f<2200 \mathrm{MHz}$, and $100 \mathrm{~m}<d_{\mathrm{BS}}<500 \mathrm{~m}$.

These results may be useful for improving the existing propagation loss models and developing the new more accurate models, including the models for the new technologies (such as 5G).

\section{References}

[1] NOKIA NETWORKS. Nokia Networks Deployment for Coverage (white paper). 20 pages. [Online] Cited 2016-03-09. Available at: http://networks.nokia.com/sites/default/files/document/nokia_depl oyment_for_coverage_white_paper_0.pdf

[2] CISCO SYSTEMS, INC. Cisco Visual Networking Index: Global Mobile Data Traffic Forecast Update, 2015-2020 (white paper). 39 pages. [Online] Cited 2016-03-17. Available at: http://www.cisco.com/c/en/us/solutions/collateral/serviceprovider/visual-networking-index-vni/mobile-white-paper-c11520862.html

[3] 4G AMERICAS. 5G Spectrum Recommendations (white paper). 28 pages. [Online] Cited 2016-03-18. Available at: http://www.4gamericas.org/files/6514/3930/9262/4G_Americas_5 G_Spectrum_Recommendations_White_Paper.pdf

[4] JAPERTAS, S., PILIPAVICIUS, K., JANARTHANAN, D. Signal propagation model for microcells at $900 \mathrm{MHz}$ frequency range. Elekronika ir Elektrotechnika, 2015, vol. 21, no. 4, p. 65-68. DOI: 10.5755/j01.eee.21.4.12786

[5] OKOROGU, V. N., ONYISHI, D. U., NWALOZIE, G. C., et al. Empirical characterization of propagation path loss and performance evaluation for co-site urban environment. International Journal of Computer Applications, 2013, vol. 70, no. 10, p. 34-41. DOI: 10.5120/12001-7888

[6] HAMID, M., KOSTANIC, I. Path loss models for LTE and LTE-A relay stations. Universal Journal of Communications and Network, 2013, vol. 1, no. 4, p. 119-126. DOI: 10.13189/ujen.2013.010401

[7] CHEBIL, J., LAWAS, A. K., RAFIQUL ISLAM, M. D. Comparison between measured and predicted path loss for mobile communications in Malaysia. World Applied Sciences Journal, 2013, no. 21, p. 123-128. DOI: 10.5829/idosi.wasj.2013.21.mae.99936

[8] RATURI, P., GUPTA, V., ERAM, S. Proposed propagation model for Dehradun region. International Journal of Soft Computing and Engineering, 2014, vol. 3, no. 6, p. 236-240. ISSN: 2231-230

[9] OSENI, F. O., POPOOLA, S. I., ABOLADE R. O., et al. Comparative analysis of received signal strength prediction models for radio network planning of GSM $900 \mathrm{MHz}$ in Ilorin, Nigeria. International Journal of Innovative Technology and Exploring Engineering, 2014, vol. 4, no. 3, p. 45-50. ISSN: 2278-3075

[10] MAWJOUD, S. A. Path loss propagation model prediction for GSM network planning. International Journal of Computer Applications, 2013, vol. 84, no. 7, p. 30-33. DOI: 10.5120/145922830

[11] ISABONA, J., KONYEHA C. C. Urban area path loss propagation prediction and optimization using Hata model at $800 \mathrm{MHz}$. IOSR Journal of Applied Physic, 2013, vol. 3, no. 4, p. 08-18.

[12] TURKKA, J., RENFORS, M. Path loss measurements for a nonline-of-sight mobile-to mobile environment. In Proceedings of 8 th International Conference on ITS Telecommunications (ITST-2008). Hilton Phuket (Thailand), 2008, p. 274-278. DOI: 10.1109/ITST.2008.4740270

[13] ZHAO, X., RAUTIAINEN, T., KALLiOLA, K., et al. Path loss models for urban microcells at $5.3 \mathrm{GHz}$. IEEE Antennas and Wireless Propagation Letters, 2006, vol. 5, no. 1, p. 152-154. DOI: 10.1109/LAWP.2006.873950

[14] BARBIROLI, M., CARCIOFI, C., ESPOSTI, V. D., et al. Characterization of WIMAX propagation in microcellular and picocellular environments. In Proceedings of the Fourth European Conference on Antennas and Propagation. Barcelona (Spain), 2010, p. 1-5. ISBN: 978-1-4244-6431-9

[15] KLOZAR, L., PROKOPEC, J. Propagation path loss models for mobile communication. In Proceedings of the 21st International Conference Radioelektronika 2011. Brno (Czech Republic), 2011, p. 1-5. DOI: 10.1109/RADIOELEK.2011.5936478

[16] POLAK, L., KLOZAR, L., KALlER, O., et al. Study of coexistence between indoor LTE femtocell and outdoor-to-indoor DVB-T2-Lite reception in a shared frequency band. EURASIP Journal on Wireless Communications and Networking, 2015, vol. 114, p. 1-14. DOI: 10.1186/s13638-015-0338-x

[17] SAMIMI, M. K., RAPPAPORT, T. S., MACCARTNEY, G. R. Probabilistic omnidirectional path loss model for millimeter-wave outdoor communications. IEEE Wireless Communications Letters, 2015, vol. 4, no. 4, p. 357-360. DOI: 10.1109/LWC.2015.2417559

[18] MACCARTNEY, G. R., ZHANG, J., NIE, S., et al. Path loss models for $5 \mathrm{G}$ millimeter wave propagation channels in urban microcells. In Proceedings of IEEE Global Communications Conference, Exhibition \& Industry Forum (GLOBECOM). Atlanta (USA), 2013, p. 3948-3953. DOI: 10.1109/GLOCOM.2013.6831690

[19] NISSIRAT, L. A., ISMAIL, M., NISIRAT, M., et al. Lee's path loss model calibration and prediction for Jiza Town, South of Amman City, Jordan at $900 \mathrm{MHz}$. In Proceedings of 4th IEEE International $R F$ and Microwave Conference (RFM). Seremban (Malaysia), 2011, p. 412-415. DOI: 10.1109/RFM.2011.6168779

[20] MARDENI, R., PEY, L. Y. Path loss model development for urban outdoor coverage of Code Division Multiple Access (CDMA) system in Malaysia. In Proceedings of International Conference on Microwave and Millimeter Wave Technology (ICMMT). Chengdu (China), 2010, p. 441-444. DOI: 10.1109/ICMMT.2010.5525001

[21] NISIRAT, M. A., ISMAIL, M., NISSIRAT, L., et al. A Hata based model utilizing terrain roughness correction formula. In Proceedings of 6th International Conference on Telecommunication Systems, Services, and Applications (TSSA). Bali (Indonesia), 2011, p. 284-287. DOI: 10.1109/TSSA.2011.6095451

\section{About the Authors...}

Saulius JAPERTAS was born in 1959. He received his Ph.D. from the Lithuanian Energy Institute in 1991. He is 
head of Telecommunications Department of Kaunas University of Technology, Lithuania. His research interests include wireless networks, security and protection of electronics and telecommunications measures.
Vitas GRIMAILA was born in 1974. He received his M.Sc. and Ph.D. from the Kaunas University of Technology in 1999 and 2004, respectively. His research interests are in the area of mobile technologies, signal propagation, and spectral resource optimization. 